Editorial

\title{
Air Pollution: Health Hazards and Prevention
}

\author{
Randeep Guleria ${ }^{1}$ Pawan Tiwari ${ }^{1}$ \\ ${ }^{1}$ Department of Pulmonary, Critical Care and Sleep Medicine, \\ All India Institute of Medical Sciences, New Delhi, India \\ J Card Crit Care TSS 2020;3:1-4
}

\section{Introduction}

Air pollution is as old or probably older than humanity itself. Charaka Samhita provides one of the earliest descriptions of polluted air and its ill effects on human health. ${ }^{1}$ John Evelyn wrote one of the first books in Western literature attributing chronic respiratory ailments to air pollution in $1661 .{ }^{2}$ However, rapid industrialization, urbanization, and increased use of fossil fuels coupled with climate change and air pollution have become a health emergency in India. Smog is an annual occurrence in New Delhi, and has been seen even in coastal areas like Chennai (Figs. 1 and 2). Annual mean particulate matter 2.5 (PM2.5) exposure in India has been estimated to be nearly $90 \mu \mathrm{g} / \mathrm{m}^{3}$, more than twice the national ambient air quality standard (NAAQS) upper limit of $40 \mu \mathrm{g} / \mathrm{m}^{3}$. More than $75 \%$ of our population has higher exposure to air pollution. Of these, New Delhi, Haryana, and Uttar Pradesh had exposure of around $125 \mu \mathrm{g} / \mathrm{m}^{3}$, that is, more than three times the upper limit. More than thrice the recommended exposure to pollutants. In India (2017), of the 1.24 million (1.09-1.39 million) deaths, that is, $12.5 \%$ of total deaths, were attributable to air pollution. Of these, 0.48 million (0.39-0.58 million) were attributable to household air pollution. Importantly, $51.4 \%$ deaths have been reported in persons below 70 years of age. In 2017, 26.2\% of the global disease adjusted life years (DALYs) associated with air pollution were contributed by India. The highest DALYs due to ambient air pollution were in Uttar Pradesh, Haryana, New Delhi, Punjab, and Rajasthan; household air pollution DALYs were highest in Chhattisgarh, Rajasthan, Madhya Pradesh, and Assam. Improvement in air pollution is estimated to improve life expectancy in 2017 by 1.7 years (1.6-1.9 years); and $>2$ years in Rajasthan, Uttar Pradesh, and $\operatorname{Haryana}^{3}$ (-Fig. 2).

The major air pollutants are PM, ozone, nitrogen oxides, carbon monoxide $(\mathrm{CO})$, and sulfur dioxide $\left(\mathrm{SO}_{2}\right)$. The larger particulate matter (PM 10, that is, particulate matter $<10$

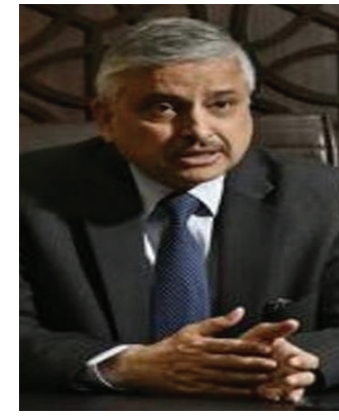

Dr Randeep Guleria $\mu \mathrm{m}$ diameter) is entrapped in upper airways, and causes rhinitis, sinusitis, and throat irritation. The finer PM, that is, PM $<2.5 \mathrm{~mm}$ (PM2.5) bypasses the natural defense of upper airways and is deposited in distal airways, enters systemic circulation, and causes increased acute cardiovascular, cerebrovascular, and respiratory events, and also chronic diseases such as asthma, chronic obstructive pulmonary disease (COPD), and lung cancer. PM exposure has also been linked to low birth weight and poor lung development. Ozone, a powerful oxidant, causes oxidative damage, leads to increased neutrophils, and inflammatory cytokines in the bronchial tree causes increased acute respiratory morbidity (pneumonia and asthma). Increasing ambient temperatures due to climate change coupled with air pollution poses a very grave public health challenge. ${ }^{4}$ Upper respiratory symptoms, namely sinusitis, running or stuffy nose, sneezing, sore throat, and common cold with fever were 1.8 times more prevalent in residents of New Delhi in the months of October and November of 2019 (personal observation, unpublished).

Vehicle exhaust, forest fires, fossil fuels, dust particles, pollution, spores, and volcanoes all aid in hastening air quality deterioration. The ongoing climate change crisis adds on to the adverse health effects of air pollution. Productivity loss from all of the above retards economic growth. A recent World Bank study estimated that for the year 2013, premature air pollution attributable deaths led to a loss of 225 billion dollar in labor income, and $\$ 5.11$ trillion welfare losses worldwide; for India, these losses accounted for more than $8 \%$ of its GDP. ${ }^{5}$

\section{Adverse Effects of Air Pollution on Health: Inhaling a Heart Attack}

Air pollution mainly affects the lungs but data increasingly shows that it affects the entire body. We have poor quality air for most days of the year in New Delhi or the Indo-Gangetic
Address for correspondence Randeep Guleria MD, DM, Department of Pulmonary, Critical Care and Sleep Medicine, All India Institute of Medical Sciences, New Delhi, India, (e-mail: randeepg@hotmail.com).
DOI https://doi.org/ 10.1055/s-0039-1701141 ISSN 2457-0206.
Copyright @2020 Official

Publication of The Simulation

Society (TSS), accredited

by International Society of

Cardiovascular Ultrasound (ISCU).

\section{License terms}

@(1) $\ominus \circledast$ 


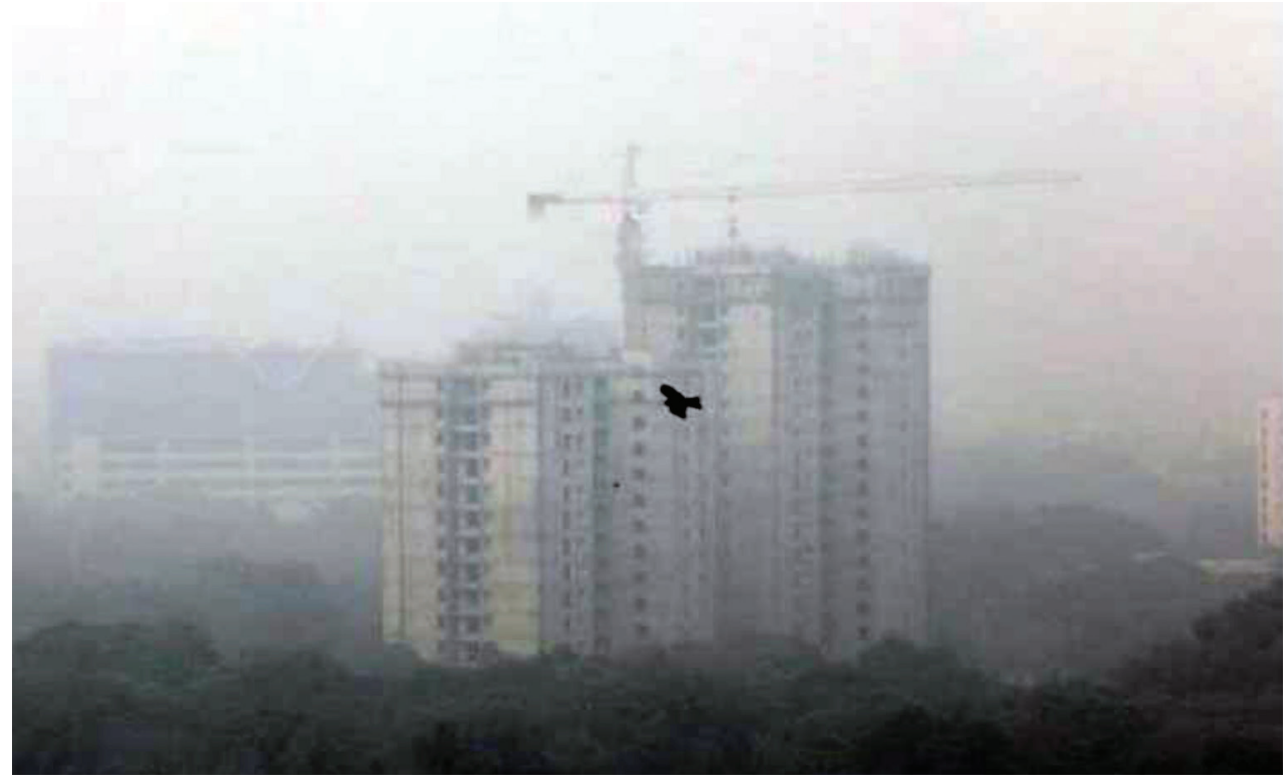

Fig. 1 A layer of smog and dust particles has turned the air quality of New Delhi National Capital Region (NCR) plunging to the severe or hazardous category, making everyone cough, causing throat irritation, and even spreading serious health risk.

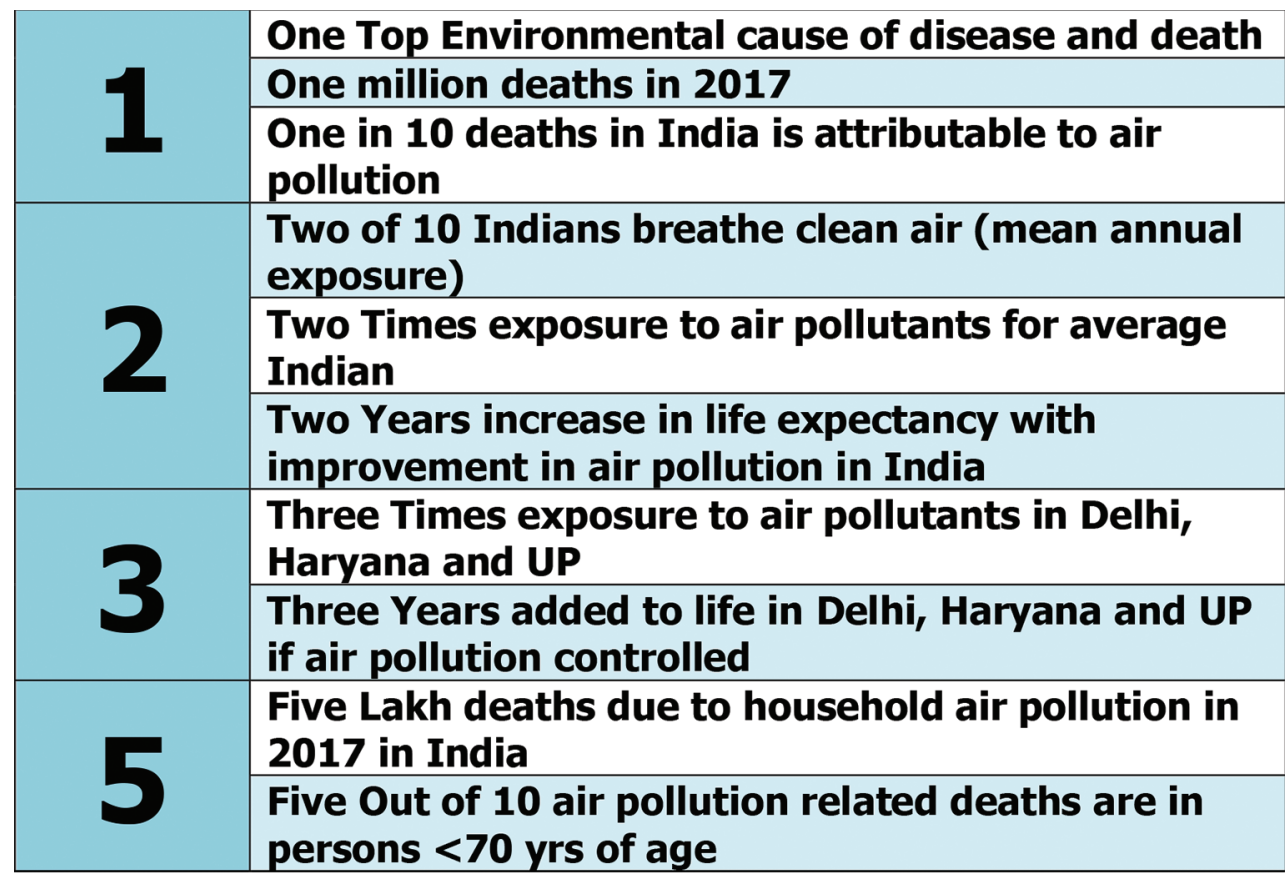

Fig. 2 Air pollution in India: current status.

belt. So what happens to people who are breathing poor quality air for more than 10 years? Apart from lung cancer, it causes inflammation in the blood vessels running through the lungs and the rest of the body. It leads to atherosclerosis or the hardening of the arteries, which predisposes people to heart attacks and stroke. Cardiac associations now believe that living in areas with higher levels of air pollution is as much a risk of heart attack as is smoking. People living in New Delhi for long are adding to the risk of heart attack and heart disease. There is a limit to what the body can adjust to. We have a reserve that stops you from becoming breathless when your lung capacity falls to some extent. But when that reserve declines with age, the chances of getting respiratory problem become higher. So chronic exposure will cause health problems in later life, even if they remain unnoticeable in the younger age group.

\section{Lung Cancer Increase Seen with Air Pollution}

Particulate matter, importantly PM 2.5 and other ambient and indoor pollutants cause airway inflammation, impair immune response, and reduce oxygen-carrying capacity of 
blood. They also cause irreversible deoxyribonucleic acid (DNA) damage. This leads to increased risk of various malignancies like upper airway and lung cancers. Ambient air pollution are associated with increased risk and mortality with lung cancer in nonsmoking adults. ${ }^{6}$ Household air pollution is also associated with increased risk of lung cancer in India, especially in nonsmoking young females. ${ }^{7,8}$

\section{Air Pollution Causes Alarming Increase in Hospital Emergency Admissions}

The short-term effects of air pollution are predominantly seen in people at high risk. Inhaling toxic substances like nitric and sulfur oxides, particulate matter, and ozone cause worsening of underlying COPD, asthma, and heart disease, leading to acute coronary syndrome, stroke, heart failure, or respiratory failure, which in turn leads to emergency visits, more medication need, and overall higher morbidity and mortality. In a recent study, the All India Institute of Medical Sciences (AIIMS) Pulmonary and Emergency Medicine team looked at hospital emergency room visits both in the pediatric and adult age group throughout the year. They observed in first and second week in November 2019, a 30\% direct correlation in a spike in casualty visits of patients with cardiac and respiratory problems in the $\mathbf{7 2}$ hours following air quality deterioration.

\section{Increase in Risk of Infections with Air Pollution}

Studies indicate increase in the risk of bacterial and viral respiratory infections with short-term changes in air pollutant levels particularly PM2.5. ${ }^{9}$ This may be due to change in composition of PM, air pollution-induced change in virulence of organisms or some unexplained cause.

\section{What Can We Do to Avoid Adverse Health Effects of Air Pollution?}

The solution lies in finding a permanent sustainable interventions to reduce air pollution and maintain air quality. Individual interventions include increasing utilization of public transport, adapting ecofriendly lifestyle, that is, walking short distances, sharing vehicles, carpooling, planting trees on occasions like birthdays or religious ceremonies, avoiding use of firecrackers, and so forth. However, legislations and stringent implementation of regulations is the need of the hour to curb the menace of air pollution in India. Observational studies have demonstrated that idling buses and passenger cars outside school lead to significant worsening of air quality, with adverse health outcomes in school children. ${ }^{10}$ Limiting vehicle idling activities and interventions such as "walk to school" have been shown to improve air quality and health outcomes. ${ }^{11}$

\section{Efficacy and Protection of Masks and Respirators}

Various types of face masks are available and are in use especially in cities like New Delhi during the times of smog or poor air quality. Triple-layered surgical masks, N95 and N99 respirators, are commonly used. However, research from China shows that commonly available masks were ineffective in preventing inhalation of polluted air, predominantly due to poor mask fitting on the face. ${ }^{12}$ Among other things are nasal filters, but these are useful for people who are at high risk or going to areas where pollution level is very high. Through schemes of Make in India and Startup India, Prateek Sharma and team ensured the global standard product at a very low cost which can be used by everyone (-Fig. 3). However, there is limited evidence for efficacy of nasal filters in allergic rhinitis in pollen season . Efficacy in air pollution needs further research .

\section{Utility of Air Purifiers for Prevention of Air Pollutant Inhalation}

Air purifiers have been demonstrated to improve indoor air quality, and improved health outcomes, predominantly in asthmatics. ${ }^{13}$ However, most of the data for air purifiers looked at a room that is properly sealed and the person is in that room for most of the day. Most of our rooms in India are not properly sealed, with air and dust entering from the windows and doors, limiting benefit of purifiers. There is no research on cost-benefit analysis of such a costly intervention. Again, like masks, it may give a little bit of reassurance but overall, it cannot be taken as a permanent solution.
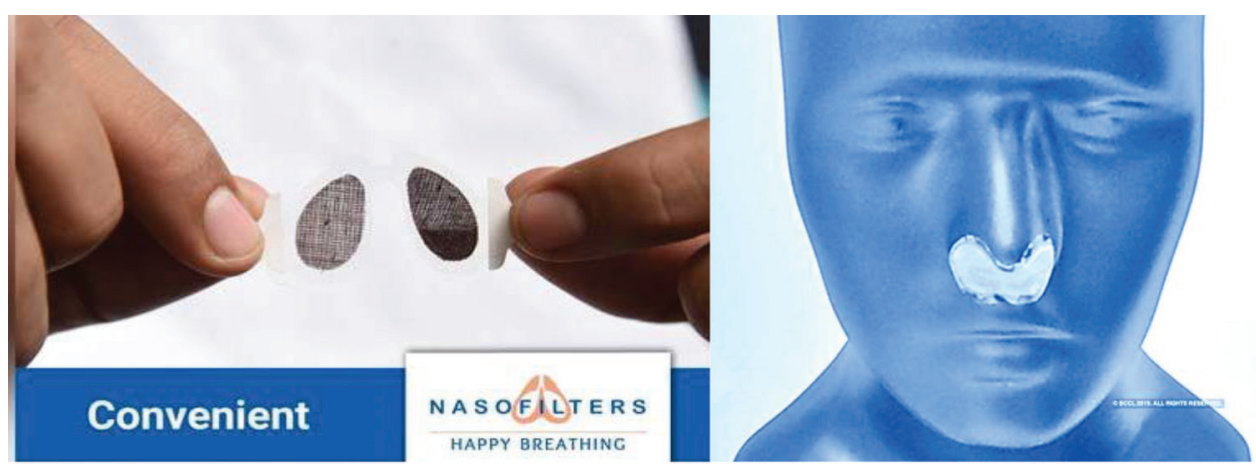

Fig. 3 Nasofilters founded by Prateek Sharma and team-Indian Institute of Technology (IIT) New Delhi startup called "Nanoclean Global." 
Table 1 Simple dos and don'ts during air pollution epidemic Sprinkle water in the morning and in the evening to avoid pollution from electronic items such as air conditioners.

Regulate daily outdoor activity keeping in mind the local air quality index (AQI)

Avoid outdoor strenuous activities especially during periods of very poor air quality.

Avoid use of fossil fuels, mosquito coils, and incense sticks inside homes to avoid indoor air pollution.

Discourage and avoid smoking inside homes, residential areas, and office premises to keep indoor air healthy.

Limit use of generators, metal ovens (tandoors), and outdoor fires for cooking and recreational purposes.

Using indoor plants which can purify the air inside the home is also advisable, to enrich indoor air.

Vaccinations are suggested to vulnerable patients, with chronic respiratory and cardiovascular diseases, malignancy, immunodeficiencies, and extremes of age.

Use good-fit personal protective equipment like N95 respirators for persons at risk.

There is no evidence that use of antioxidants or herbal medications helps protects from adverse health effects of air pollution.

The use of public transport must be increased and individual vehicles avoided as much as practically possible.

\section{Utility of Exercise When Air Pollution is Severe}

Recent research from the United Kingdom demonstrates that the benefits of cardiopulmonary effects of walking are undone by short-term exposure to traffic related air pollution in healthy adults as well as older adults with cardiorespiratory disease. ${ }^{14}$ However, the levels of exposure in India may be multiple folds higher, and cause adverse health effects. Therefore, one should avoid aggressive outdoor exercise during periods of high air quality index (AQI). After sunrise, as the ambient temperature increases, there is some improvement in air quality. So, one may shift the outdoor exercise timings to later in the day, that is, at lunch time. It is important, however, to continue physical activities and exercises due to long term health benefits.

\section{Here's How to Survive from Hazardous Air Pollution in New Delhi}

As the Environment Pollution (Prevention and Control) Authority has declared a public health emergency in the national capital in view of the abysmal AQI, people should take certain precautions to protect their health (- Table 1).

\section{Conclusion}

Air pollution remains a serious health hazard in India and is the most important environmental cause of morbidity.
Almost all ages and organ systems can be affected due to air pollution, by both acute and chronic effect. Control of airborne pollution requires sustained and coordinated efforts at all levels ranging from effective health education to preventive community, social, individual, political governance, and administrative approaches. A combined efforst in an integrated manner alone will yield clean air for us in 2020 .

\section{References}

1 James GA, Ethical Perspectives on Environmental Issues in India. New Delhi, India: APH Publishing; 1999

2 Wikipedia. Fumifugium. https://en.wikipedia.org/wiki/Fumifugium. Accessed November 25, 2019

3 Balakrishnan K, et al; India State-Level Disease Burden Initiative Air Pollution Collaborators. The impact of air pollution on deaths, disease burden, and life expectancy across the states of India: the Global Burden of Disease Study 2017. Lancet Planet Health 2019;3(1):e26-e39

4 Carrington D. Climate change to cause humid heatwaves that will kill even healthy people. The Guardian. August 2, 2017

5 Bank TW. The cost of air pollution : strengthening the economic case for action. http://documents.worldbank.org/ curated/en/781521473177013155/The-cost-of-air-pollutionstrengthening-the-economic-case-for-action. Published 2016 Accessed November 25, 2019

6 Chen G, Wan X, Yang G, Zou X. Traffic-related air pollution and lung cancer: a meta-analysis. Thorac Cancer 2015;6(3):307-318

7 Kurmi OP, Lam KBH, Ayres JG. Indoor air pollution and the lung in low- and medium-income countries. Eur Respir J 2012;40(1):239-254

8 Behera D, Balamugesh T. Indoor air pollution as a risk factor for lung cancer in women. J Assoc Physicians India 2005;53:190-192

9 Croft DP, Zhang W, Lin S, et al. The association between respiratory infection and air pollution in the setting of air quality policy and economic change. Ann Am Thorac Soc 2019;16(3):321-330

10 Richmond-Bryant J, Bukiewicz L, Kalin R, Galarraga C, Mirer F. A multi-site analysis of the association between black carbon concentrations and vehicular idling, traffic, background pollution, and meteorology during school dismissals. Sci Total Environ 2011;409(11):2085-2093

11 Ryan PH, Reponen T, Simmons M, et al. The impact of an antiidling campaign on outdoor air quality at four urban schools. Environ Sci Process Impacts 2013;15(11):2030-2037

12 Cherrie JW, Apsley A, Cowie H, et al. Effectiveness of face masks used to protect Beijing residents against particulate air pollution. Occup Environ Med 2018;75(6):446-452

13 Vijayan VK, Paramesh H, Salvi SS, Dalal AAK. Enhancing indoor air quality-the air filter advantage. Lung India 2015;32(5):473-479

14 Sinharay R, Gong J, Barratt B, et al. Respiratory and cardiovascular responses to walking down a traffic-polluted road compared with walking in a traffic-free area in participants aged 60 years and older with chronic lung or heart disease and age-matched healthy controls: a randomised, crossover study. Lancet 2018;391(10118):339-349 